https://doi.org/10.48009/1_iis_2005_197-203

\title{
IF YOU BUILD IT, WILL THEY COME? CHALLENGES IN E-LEARNING DELIVERY SYSTEM CHOICE
}

\author{
Dr. Jane Saber, University of Texas at Tyler, jsaber@uttyler.edu \\ Dr. Isaura Flores, University of Texas at Tyler, iflores@uttyler.edu \\ Dr. Mary Helen Fagan, University of Texas at Tyler, mfagan@uttyler.edu \\ Dr. Carol Kilmon, University of Texas at Tyler, ckilmon@uttyler.edu \\ Dr. Janith Williams, University of Texas at Tyler, jwilliams@uttyler.edu \\ Kristina Ibitayo, University of Texas at Arlington, ksi4274@exchange.uta.edu
}

\begin{abstract}
This study incorporates principles derived from 'mindful technology adoption', instructional design, technology acceptance models, and target learner needs assessments in order to determine whether or not e-learning technologies would be used by multi-organizational health administrators in their re-accreditation processes. It was initially hypothesized that these nontraditional, geographically dispersed, computer literate learners would be likely to use the elearning technologies, due to course flexibility, their full time work status, age and other variables. Results indicate that the sample had lower than expected intentions to use online learning resources, predictions that they would to use online learning resources, and plans to use an online learning system. The design of this study and its results are a case study that lends support for the need for mindful adoption of e-learning technologies. A needs assessment addressing the likeliness of technology acceptance is a critical first step in designing e-learning delivery systems, in order to ensure that e-learning technology investments are worthwhile.
\end{abstract}

Keywords: Mindful technology acceptance, e-learning, training needs assessment, health care

\section{INTRODUCTION}

Distance education using electronic mediums has been growing at an extraordinary rate. For example, considering only U.S. corporate e-learning, the value of this market was estimated at 5 billion dollars in 2004, and is expected to grow to 13.48 billion dollars by 2008 [4]. From this perspective, development of effective e-learning models and systems is likely to be a priority for many organizations in the future.

Academics have also been extensively investing in e-learning research and development. A literature review for the period 1987-2005 identified over 3500 articles on distance education and e-learning, with research topics ranging from technology acceptance models $[13,6]$, to student and faculty satisfaction and performance [14], the relationship between individual characteristics and e-learning environments and a multitude of other factors. The cautious, but generally positive results of the research findings, combined with the possibility of increased profitability and larger learner market share, has led to the almost wholesale adoption of e-learning delivery systems by universities and other training organizations [8].

In the race for e-learning adoption, however, organizations may be minimizing the importance of the basic principles of instructional design. In particular, in order to successfully 'sell' an 
educational product or service, the e-provider must determine both the perceived and actual needs and benefits that the target learner derives from the offering and develop the product to reflect those needs and benefits [3]. Thus, in order to prepare an appropriate training program, the organization must first perform a training needs analysis. This research is a case study that illustrates how training needs assessments can dispel erroneous assumptions about target learners and also highlights the potential significant negative consequences of inadequately addressing this critical initial step.

\section{CONTEXT AND MOTIVATION FOR RESEARCH}

This study represents a collaborative effort of a College of Business and Technology and a School of Nursing, and was funded by a Congressional Grant from the Department of Education. The study is partially in response to a serious deficit of nursing faculty [2], resulting in over 2,200 qualified applicants being unable to participate in nursing training. In addition, registered nurses and other related health practitioners are required to undergo at least twenty hours of certified continuing education training for re-accreditation. These requirements, and the fact the fact that many of the potential learners were located in relatively remote areas, have caused addition resource strain on a training system already stretching to fully serve its target market.

As a result of these challenges, the researchers initiated an investigation into of e-learning as a potential educational delivery option. Rather than simply developing e-curriculum, based on explicit and inferred assumptions about these non-traditional, multi-organizational target learners and their needs and benefits, the research team recognized that "technological potentials do not easily transfer into direct educational benefits" [15], and that training is not transferred back to the workplace over fifty percent of the time [9]. Because of this, and the theoretical underpinnings of instructional systems design and technology acceptance literatures, the researchers completed an initial needs assessment to determine the suitability of e-learning to its target learners.

\section{LITERATURE AND RESEARCH DEVELOPMENT}

The theoretical foundations of this study arose from the amalgamation of principles derived from research on 'mindful adoption of technology development', models of instructional systems development, technology acceptance models, and previous needs assessments for health workers. Although an extensive review of this literature is beyond the scope of this paper, a concise overview of these literatures is as follows.

Mindfulness in technology adoption is a principle described by Swanson and Ramiller [12] which encourages organizations to critically analyze any technology adoption intentions, rather than simply accepting the industrial-community commonly accepted practices. Five characteristics of mindful technology adoption include: 1) not taking generalized claims about the innovation's benefits and applicability at face value but instead critically examine their local validity, 2) critically examining rationale for adoption in wider community, 3) fashioning unique rationale for technology adoption, based on the rich context of the specific organizational decision making , 4) not necessarily taking the early adopter stance for the sake of it, 5) employing a clear implementation strategy, if the technological acceptance appears sound. According to the authors, mindless technology adoption can lead to the 'bandwagon phenomena' 
[1], which is the implementation 'me too' strategies in order to keep up with the organizational processes of the adopting community or industry. Although mindless adoption may be strategic, it may also lead to unforeseen and / or undesirable organizational consequences such as substantial technological investments that will not actually be used.

In our research context, a number of factors could have easily led to a mindless decision of elearning technology adoption. First, it was clear that there is widespread e-provider community adoption of e-learning technologies. Second, there was a pressing need for alternative methods of course delivery due to faculty shortages. Third, the College of Nursing had technological resources and funding available for e-delivery development. Because of these factors, e-delivery development would have been a very likely next step. Instead, the researchers chose to implement the first characteristic of mindful adoption and critically examine the target learners and learning context in order to ensure the usefulness and effectiveness of e-learning delivery options. In order to accomplish this goal, the researchers utilized a training needs assessment tool, based on the principles of instructional design, as follows.

There are a number of instructional design and training needs assessment models that were considered in the structuring of the research design employed by this study. The ADDIE (IPISD) model is a systematic approach to instructional development whereby five major processes are undertaken to establish effective instructional design: analysis, design, development, implementation and evaluation [11]. The instructional systems design model (ISD) is another approach, the steps of which are: 1) the analysis of performance problem, in order to find underlying causes, 2) examining work requirements to determine any problems rooted in lack of individual knowledge, skills or attitudes, 3) a training needs assessment, which identifies what workers must do to perform at work, 4) writing instructional objective in training, 5) decide to buy or make training content, 6) decide on delivery systems. Another model, the Strategic Systems Model, (SSM), focuses on discovering differences between exemplary and successful performers and requires: front-end needs analysis, assessment and planning aligned with the organization's s goals and plans, competency model development, curriculum planning, learning intervention design, development and delivery and evaluation [7].

The researchers recognized the usefulness for organizational, task and individual levels of analysis for a complete needs assessment [5]. However, the sample was derived from multiple, geographically dispersed organizations that were unrelated except for general industry categorization, and, as a result, were likely to have unique organizational needs and goals. Therefore, a needs assessment approach was used which relied on target learner identification of preferences, rather than organization-specific issues and competencies. The public health literature provided non-organization specific universal competencies that should be addressed in health training, generally including issues in data analysis, communications, policy and program planning, culture, basic science, finance and management, and an orientation to public health [10]. Based on this literature, and the results of depth interviews and focus groups, survey questions presenting training priorities were developed.

In addition to the needs assessments on training priorities, in order to determine the likeliness of e-learning delivery acceptance, this study utilized the theoretical contributions of the technology acceptance model research. Although a full discussion of the technology acceptance and 
diffusion models is not possible here, [6] because of the greater explanatory power of the model established by Venkatesh [13], the Unified Theory of Acceptance and Use of Technology (UTAUT) was the measure used in this research.

\section{METHOD}

Data was collected using a survey, which was designed based on depth interviews, secondary research, and several focus groups. The sample was office managers in the East Texas area, who often had dual roles as managers and health care practitioners. The sample was selected from a list provided by the InfoUSA and confirmed in a Department of Health list. Once validated, surveys were sent to all participants on the list for a total of approximately 420 surveys.

Participants were identified as the office managers on record at each location. A small incentive was used to ensure participation and a total of 90 participants returned their surveys for a participation rate of approximately $21 \%$. Nine surveys were unusable, due to missing data. This relatively low response rate, compared to other training need studies, was likely due to a number of issues: there was no organization-'mandated' managerial request to complete the survey and there may have been a lack of salience or relevance of the subject matter of the survey for reasons which will be discussed.

The survey was designed to capture a variety of relevant factors: organizational characteristics, personal characteristics, course training needs and preferences, barriers to e-learning acceptance, and likeliness of e-learning use. Descriptive results and results for usefulness, ease of use, and intention, predication and plans to use online learning resources are reported, as follows. The main hypotheses that were tested were that health care managers would find online technologies easy to use, useful, and that they would be likely to plan, intend and predict online technology usage.

\section{RESULTS}

With respect to organizational characteristics, there were a diverse range of types of practice, affiliations with different clinics and hospitals, number of staff, and composition of patients gathered in this study. $51 \%$ of respondents were employed by a clinic and $49 \%$ by a hospital or related organization. The mean number of people working in each office, including all categories of nurses and doctors was approximately 8 people who served approximately 182 patients per week. With respect to personal demographic characteristics, the sample was approximately $80 \%$ female, with $57 \%$ of the sample ranging in age from $35-54.56 \%$ of the sample had nursing certification or higher education, $74 \%$ had spent 7-9 years in health care, and $63 \%$ had spent 7-9 years in health care management. $80 \%$ of the sample had been in their current position for more than 4 years. Over $90 \%$ of the sample had taken at least one professional course in the past year.

With respect to Internet and WWW experience, only $7.5 \%$ of respondents listed themselves as inexperienced with these technologies. With respect to online learning courses, $57 \%$ classified themselves as inexperienced, $41 \%$ as moderately experienced, but only $2 \%$ as very experienced. Thus, although many respondents are quite familiar with the new information technologies, few were experienced with online courses. This pattern of distribution is not unexpected, however, given the relative newness of this type of course delivery system. With respect to access to 
computers, $100 \%$ of the respondents had access to computers and software, $84 \%$ had access both at home and at work, and over $63 \%$ had access to a cable modem at both locations. Thus, access to equipment to complete online courses did not seem to be an important barrier to technological adoption here.

With respect to training programs needs, course offerings were categorized on a 5 point Likert scale, where 5 represented the response "definitely will participate", 3 representing the "not sure' response, and 1 representing the response 'definitely will not participate'. Interestingly enough, despite the course selections being gleaned from the core health care competency literature, depth interviews and focus group results, the range of scores was from approximately 2.2 to 3.1, with standard deviations of responses ranging from .98 to 1.2. These results indicate a lack of commitment to any of these subject matters, and could imply a lack of salience, relevance or enthusiasm for all course materials, even though the list was reasonably exhaustive (40 course types listed). This issue will be further discussed. The ranking of the course delivery system, on a five point Likert scale from most to least preferred, were video conferences (3.00), videotapes (2.73), CDROM, (2.43), and Internet (1.90), all of which had standard deviations very close to 1. Factors which may prevent participation in health training programs, listed from most likely to prevent participation to least likely to prevent participation were relevance, family obligations, no time to leave work, no desire to use up vacation time on coursework, no financial support, and finally, no employer support.

Descriptive results regarding behavioral intentions were measured using a 7 point Likert scale ranging from strongly agree (1), to neutral (3), to strongly disagree (7). These results indicated that, although participants did not seem to be intimidated using the technologies, $(\mathrm{m}=4.79$, s.d=1.57), for the most part, they did not conclusively plan $(\mathrm{m} .=3.97$, s.d. $=1.49)$, predict $(\mathrm{m}=3.89$, s.d. $=1.47)$ or intend to use online learning resources $(\mathrm{m} .=3.95, \mathrm{~s} . \mathrm{d} .=1.48)$. T-test results on these three behavioral measures (intention: $\mathrm{t}_{80}=5.771, \mathrm{p}<.001$, prediction, $\mathrm{t}_{80}=5.456$, $\mathrm{p}<.001$, plan: $\left.\mathrm{t}_{80}=5.885, \mathrm{p}<.001\right)$ were significantly lower than a neutral score. These results occurred despite the fact that the sample thought that online learning technologies were relatively easy to use, $(\mathrm{m} .=2.59$, s.d. $=1.22)$ and useful $(\mathrm{m} .=2.43$, s.d.= 1.38). For the most part, these results are consistent with the ranking of the course delivery systems, which showed online courses (Internet) as the least desired course delivery system. Regression analysis, using each of the three behavioral measures separately, (predict, plan, and intend), and the variables sex, size of organization, level of web experience, level of online experience, past year level of course participation and access to computers had very low adjusted $\mathrm{R}^{2}$ values $(.108, .088$ and .052 , respectively) and none of the demographic or experience variables were significant in any of the regression equations. Clearly, some factors other than the ones investigated in this data analysis were responsible for the low levels of the behavioral measures. This question will be investigated in future research.

\section{DISCUSSION AND IMPLICATIONS}

Contrary to research hypotheses, initial data analysis indicated that this sample of potential elearners were somewhat unlikely to choose online technologies for their educational requirements, despite the fact that they found online technologies useful and easy to use. Discussions of these results with industry experts and an examination of the learning context 
may give some insight as to why these results have occurred as follows. First, as shown in the results, the sample did not see training courses, generally, as relevant. This fact was confirmed in the expert discussions. Second, many of the continuing education courses are evaluated based on attendance only, and give a grade of 'pass or fail'. Given the perceived job irrelevance of the courses and the lack of rigorous testing procedures to evaluate learning, the motivation to learn is likely to be fairly low. As such, these target learners may be looking for the least effort method of complying with re-accreditation requirements. This may be particularly true for the majority of the sample who have been at their current positions for more than seven years: it may be that initially courses are seen as relevant, but after a number of perceived irrelevant course experiences, the expectation of irrelevance may form and color all other opportunities for learning. In addition, there are likely other factors that also contribute to the low levels of intention, prediction and planning of these learners, and these will be explored in future SEM analysis of the UTAUT model. Based on these results, it would appear that further study is necessary before investing in new online learning curriculums for these learners. Representatives from the target population will need to be included in program development and testing.

The general implications of this study are as follows. First, this study serves as a caution against the mindless adoption of new e-learning technologies, without first determining the needs and preferences of the target learners. This study also re-affirms the necessity of following instructional design models, and in particular, analyzing the training needs of learners and / or organizations, prior to the development of any training programs, electronic or otherwise. Had the researchers not mindfully analyzed the e-learning potential of these learners, it is possible that a substantial financial and time investment would have been made into e-learning delivery systems that might not have been used. Finally, this study can be used as an impetus to further determine why some target learners prefer not to use online technologies and ascertain whether or not a communication strategy to increase the behavioral intentions of the target learner may be effective in the future.

\section{LIMITATIONS AND FUTURE RESEARCH}

There are a number of limitations of this research. First, because of the low response rates, relative to other training needs assessment studies, the results of this study may not be generalizable. Second, because of the specific context of health re-accreditation training, (irrelevance of courses, probable low motivation to learn), these results are also likely not generalizable to learners not sharing a similar course choice context. Further, the sample size may be too small as to provide a generalizable finding.

A number of directions for future research are anticipated from these findings. First, the data will be further analyzed using SEM and all of the UTAUT, organizational and individual variables (performance expectancy, effort expectancy, attitude toward using technology, social influence, facilitating conditions, self-efficacy, anxiety and behavioral intentions to use the system) in order to determine if whether or not any of those variables contribute to the relatively low level of online technology preference. In addition, further depth interviews, focus groups, and an openended survey will be administered to determine if the assessment of irrelevance-low learning motivation postulated above is accurate. If this is the case, not only will course subject offerings need to be investigated, but also, methods to reduce perceptions of irrelevance, including 
communication strategies of offerings should be implemented. A longitudinal design for this research could also be employed. Finally, organization-specific, SSM based training needs analysis may be completed.

The results of this study clearly show that exemplary e-learning design is much more complicated than simply adopting e-learning technologies. Mindfulness in technological adoption is critical.

\section{REFERENCES}

1. Abrahamson, E. (1991) Managerial fads and fashions: The diffusion and rejection of innovations. Academy of Management Review, 16(3), 586-612.

2. American Association of Colleges of Nursing, (2003). AACN White Paper: Faculty shortages in baccalaureate and graduate nursing programs. Retrieved June 6, 2004 from http:// www.aacn.che.edu/ Publications/ Whitepapers /Facultyshortages.htm.

3. Bettman, J.R., Johnson, E.J. \& Payne, J.W. (1998). Consumer Decision Making. In T.S. Robertson, \& H.H. Kassarjian, (Eds.) Handbook of Consumer Behaviour, Upper Saddle River, NJ: Prentice Hall.

4. Bounds, G., Compliance regulations create a software niche, Wall Street Journal Online. Retrieved February 20, 2005 from http://www.startupjounal.com/columnists/enterprise/20050224-bounds.html

5. Brown, J., (2002) Training needs assessment: A must for developing an effective training program. Public Personnel Management, 31(4), 568-579.

6. Davis, F. (1989). Perceived usefulness, perceived ease of use and user acceptance of information technology. MIS Quarterly, 13(3), 319-340.

7. Dubois, D. \& Rothwell, W. (2004) Competency-based or traditional approach to training? $T+D, 58(4), 46-58$.

8. Dyrud, M.A. (2000). The third wave: A position paper. Business Communication Quarterly, 63(3), 81-93.

9. Ford, D.J. (1999). Bottom-Line Training. Houston: Gulf Publishing Co.

10. Gould, D., Kelly, D., White, I. \& Chidgey, J. (2004) Training needs analysis: A literature review and reappraisal. International Journal of Nursing Studies, 41(5), 471-486.

11. Gufstafson, K.1., \& Branch, R. M. (2002). What is Instructional Design? In R.A. Reiser, \& J.V. Dempsey, (Eds.) Trends and Issues in Instructional Design and Technology. Columbus, $\mathrm{OH}:$ Merrill Prentice Hall.

12. Swanson, E.B. \& Ramiller, N.C. (2004). Innovating mindfully with information technology. MIS Quarterly, 28(40), 553-584.

13. Venkatesh, V., Morris, M.G., Davis, G.B. \& Davis, F.D. (2003) User acceptance of information technology: Toward a unified view. MIS Quarterly, 27(3), 425-478.

14. Webster, J. \& Hackley, P. (1997). Teaching effectiveness in technology-mediated distance learning. Academy of Management Journal, 40(6), 1282-1309.

15. Zhao, Yong (1998). Design for adoption: The development of an integrated web-based education environment. Journal of Research on Computing in Education, 30(3), 307-399. 